
KEMAMPUAN MENYUNTING KARANGAN SISWA KELAS IX SMPN 1 CIMANGGU

(Studi Eksperimen terhadap Siswa Kelas IX SMPN 1 Cimanggu)

Tina Rustina

Tina kartini@gmail.com

Universitas Muhamadiyah Sukabumi

\begin{abstract}
Abstrak. Penelitian ini dilakukan untuk mendeskripsikan langkah-langkah model kooperatif Think Pair Share dalam pembelajaran menyunting karangan serta hasil menyunting sebelum dan setelah implementasi. Tempat penelitian ini dilakukan di SMPN 1 Cimanggu tahun ajaran 2019/2020. Metode penelitian yang digunakan adalah metode eksperimen. Prosedur penelitiannya dilakukan dengan tiga tahapan yaitu pelaksanaan tes awal menyunting karangan, penerapan Think Pair Share dan tes akhir menyunting karangan. Teknik pengambilan sampel yang digunakan adalah purposive sampling dengan berdasarkan karakteristik dan rekomendasi guru pengampu mata pelajaran bahasa Indonesia. Sampel yang dipilih yaitu siswa kelas IXA. Hasil penelitian ini menunjukan bahwa penerapan Think Pair Share dalam pembelajaran dapat dilakukan dengan tahapan sebagai berikut, yaitu: 1) pendahuluan pembelajaran dengan penyampaian tujuan pembelajaran menyunting karangan; 2) pembentukan kelompok belajar; 3) pemberian stimulus menyunting karangan yang difasilitasi oleh guru; 3) mengdeintifikasi permasalahan mengenai proses menyunting karangan; 4) mengumpulkan data dari berbagai sumber mengenai proses menyunting; 4) mengolah data yang diperoleh dengan bimbingan guru melalui penyuntingan karangan; 5) menyampaikan hasil diskusinya, dan 6) menyimpulkan proses menyunting. Adapun hasilnya terdapat kenaikan yang signifikan dari rata-rata tes awal sebesar 68 menjadi 77 .
\end{abstract}

Kata Kunci: Pembelajaran, menyunting, Think Pair Share.

Abstract. This research was conducted to describe the steps of the Think Pair Share cooperative model in learning to write essays and to edit results before and after implementation. The place of this research was conducted at SMPN 1 Cimanggu in the 2019/2020 school year. The research method used is an experimental method. The research procedure is carried out in three stages, namely the implementation of the initial test editing essay, the application of Think Pair Share and the final test editing essay. The sampling technique used was purposive sampling based on the characteristics and recommendations of Indonesian language teaching teachers. The selected sample is IXA grade students. The results of this study indicate that the application of Think Pair Share in learning can be done with the following stages, that is: 1) introduction to learning by delivering learning objectives to edit essays; 2) the formation of study groups; 3) providing stimulus editing essays facilitated by the teacher; 4) identify issues regarding the editing process of the essay; 5) collecting data from various sources regarding the editing process; 6) processing the data obtained with the guidance of the teacher through editing the essay; 5) convey the results of the discussion, and 6) concludes the editing process. As for the results there was a significant increase from the average initial test of 68 to 77.

Keywords: learning, editing, Think Pair Share, editing. 


\section{PENGARUH MODEL PEMBELAJARAN THINK PAIR SHARE TERHADAP KEMAMPUAN MENYUNTING KARANGAN SISWA KELAS IX SMPN 1 CIMANGGU}

(Studi Eksperimen terhadap Siswa Kelas IX SMPN 1 Cimanggu)

\section{PENDAHULUAN}

Kurikulum 2013 merupakan suatu kurikulum yang dibentuk untuk mempersiapkan generasi emas bangsa Indonesia dengan sistem dimana kegiatan belajar mengajar yang lebih aktif. Berdasarkan kurikulum 2013 pembelajaran bahasa Indonesia di SMP meliputi tiga hal, yaitu sikap, pengetahuan dan keterampilan.

Kurikulum 2013 yang berbasis karakter dan kompetensi, antara lain ingin mengubah pola pendidikan dari orientasi terhadap hasil dan materi ke pendidikan sebagai proses, sehingga sangat berdampak pada keberhasilan siswa. Salah satu keterampilan berbahasa yang penting dikuasai, khususnya oleh siswa adalah menulis. Menulis merupakan proses menuangkan pikiran dalam menyampaikannya kepada khalayak (Kartono, 2009:17).

Tarigan (2008:3) mengatakan, "Menulis merupakan keterampilan berbahasa yang dipergunakan untuk berkomunikasi secara tidak langsung, tidak secara tatap muka dengan orang lain”. Menulis merupakan komunikasi tidak langsung dengan orang lain, jadi menulis digunakan untuk berbahasa namun dengan cara komunikasi tidak langsung. Pada pelajaran Bahasa Indonesia terdapat empat keterampilan, yaitu mendengarkan, berbicara, membaca, dan menulis.

Pendapat lain juga dikemukakan oleh Nurjamal, Daeng dalam Sumirat, Darwis (2011:69) mengatakan, "Menulis sebagai sebuah keterampilan berbahasa adalah kemampuan seseorang dalam mengemukakan gagasan, perasaan dan pemikiran-pemikirannya kepada orang atau pihak lain dengan menggunakan media tulisan". Bahwa menulis merupakan sebuah keterampilan berbahasa seseorang dalam menuangkan gagasan, perasaan dan pemikiranpemikiran dengan cara meng-gunakan media tulisan. Keterampilan menulis peserta didik perlu diperhatikan oleh para pendidik, hal ini untuk menunjang keberhasilan dalam prestasi akademik di sekolahnya.

Biasanya, kelemahan siswa yang menonjol dalam hal menulis adalah siswa kurang mampu menerapkan kaidah ejaan secara tepat. Ketika siswa mendapatkan tugas untuk menulis sebuah karangan, tanpa memperhatikan apakah hasil tulisannya sudah benar ataukah masih ada kesalahan, siswa langsung menyerahkan hasil tulisannya itu kepada guru. Siswa tidak menyunting terlebih dahulu hasil tulisannya, sedangkan dari pihak guru hanya melihat hasil akhir tulisan siswa tanpa ada tindak lanjut untuk menganalisis kesalahan penulisan, mengoreksi, dan memberitahukan kepada siswa mengenai tulisan yang benar.

Pengembangan kemampuan menyunting karangan perlu mendapat perhatian yang sungguh-sungguh karena kemampuan ini melatih siswa untuk menggunakan bahasa dengan benar, khususnya dalam hal menulis. Selain itu, kemampuan ini dapat melatih siswa untuk menjadi seorang penyunting yang dapat menghasilkan karya yang bisa diterbitkan di media massa.

Kemampuan menyunting karangan ini tidak akan datang dengan sendirinya secara otomatis, melainkan harus melalui tahap, latihan, praktik yang baik dan teratur. Dalam pelaksanaan pembelajaran menyunting karangan, siswa dalam melaksanakan kegiatan menyunting masih menyimpang, ini terlihat ketika mereka menuliskan idenya yang tidak logis dan sistematis sebagai akibat dari seringnya mengulang kesalahan dalam menulis dalam pembelajaran menyunting di sekolah, hal yang harus dikuasai, yakni penggunaan ejaan dan tata bahasa, diksi, keefektifan kalimat, serta kepaduan paragraf. Mengingat realita yang terjadi, banyak siswa yang belum dapat menyunting karangan dengan baik dan benar sehingga tidak dapat memenuhi KKM (Kriteria Ketuntasan Minimal) yang telah diberlakukan di setiap sekolah maka diperlukan perubahan dalam hal sistem pembelajaran. KKM khususnya mata pelajaran bahasa dan sastra Indonesia harus mencapai nilai 70 atau $75 \%$ mata 


\section{PENGARUH MODEL PEMBELAJARAN THINK PAIR SHARE TERHADAP KEMAMPUAN MENYUNTING KARANGAN SISWA KELAS IX SMPN 1 CIMANGGU}

(Studi Eksperimen terhadap Siswa Kelas IX SMPN 1 Cimanggu)

pelajaran harus dapat dikuasai oleh setiap siswa. Setiap siswa harus mampu menguasai kompetensi dasar yang ada tak terkecuali menyunting karangan.

Berdasarkan hasil wawancara yang dilakukan pada guru mata pelajaran Bahasa dan Sastra Indonesia di SMP Negeri 1 Cimanggu, hampir 70\% siswa khususnya Kelas IX belum dapat menyunting karangan dengan baik. Adapun yang menjadikan rendahnya kemampuan siswa dalam menyunting karangan, yaitu (1) kurangnya pemahaman siswa tentang EYD; (2) siswa kurang menguasai tata tulis yang benar; (3) siswa merasa kurang tertarik dengan pembelajaran menyunting karangan karena beranggapan bahwa menyunting karangan sangat rumit dan membutuhkan pengetahuan yang baik.

Sehubungan dengan upaya meningkatkan kemampuan menyunting karangan pada siswa, pemilihan model pembelajaran yang tepat merupakan solusi untuk meningkatkan motivasi siswa dalam belajar. Dewasa ini kecenderungan dalam dunia pembelajaran bahwa siswa akan belajar lebih baik apabila pembelajaran diciptakan oleh guru secara menyenangkan. Oleh sebab itu, penelitian ini berusaha menghadirkan model pembelajaran kooperatif think pair share yang mengutamakan kerja sama dari semua pihak dalam pembelajaran.

\section{KAJIAN PUSTAKA}

\section{Pengertian Karangan}

Menurut Kamus Besar Bahasa Indonesia (2001:393) Karangan adalah hasil mengarang, tulisan, cerita, artikel, buah pena. Jadi karangan merupakan suatu hasil buah pena atau hasil ungkapan gagasan yang disampaikan secara tertulis.

$$
\text { Karangan adalah bentuk }
$$
ungkapan atau penyampaian gagasan dengan bahasa tulis (Suparno dan M.Yunus, 2010:31). Karangan adalah pemaparan suatu gagasan secara resmi dan teratur tentang suatu topik atau pokok bahasan. Setiap karangan yang ideal pada prinsipnya merupakan uraian yang lebih tinggi atau lebih luas dari alinea (Pratiwi, 2008:6.37).

Karangan terdiri dari beberapa paragraf yang masing-masing berisi pikiran-pikiran utama dan kemudian diikuti dengan pikiran penjelas (Widjono, 2007:175). Dengan demikian, karangan merupakan hasil gagasan yang dituangkan dalam bentuk bahasa tulis berupa beberapa kalimat yang membentuk paragraf yang dapat dibaca dan dipahami pembaca.

\section{Menyunting Karangan}

Menurut Hartono A (2010:8)

Menyunting merupakan proses menyusun tulisan supaya lebih layak terbit dengan cara membaca secara teliti, mengoreksi menandai kesalahan, mengoreksi, memperbaiki naskah, dan menentukan kelayakan naskah, baik segi organisasi, kebenaran dan kelayakan isi, pemakaian bahasa, sistematika tulisan yang disajikan dalam konteks kebangsaan.

Penyuntingan karangan merupakan proses memperbaiki tulisan supaya terhindar dari ketidaktepatan tulisan sehingga tulisan tersebut menjadi sangat layak baca (Marantika, 2010:87).

Berikut ini merupakan beberapa tanda yang biasa digunakan oleh penyunting untuk memperbaiki tulisan.

a. Tanda seperti $\mathrm{x}$, biasanya dipakai untuk kalimat yang tidak digunakan. Contoh : Rumah sahabatku terbakar. $\mathrm{x}$

b. Tanda seperti $\mathrm{O}$, baiasanya dipakai untuk mengganti kata, huruf atau kalimat. Contoh : Rumah Drs. Rudiyanto di Bogor, $\mathrm{O}$

c. Tanda seperti $\sim$, biasanya dipakai untuk mengubah posisi kalimat atau kata. Contoh : Kamu rusha $\rightarrow$ harus

3. Model Pembelajaran Think Pair Share Model Pembelajaran think pair share atau berpikir berpasangan berbagi adalah merupakan jenis pembelajaran kooperatif yang dirancang untuk mempengaruhi pola interaksi siswa.

Ujang S. Hidayat (2016:104) menyatakan bahwa Model Pembelajaran kooperatif tipe think pair share menggunakan model diskusi berpasangan yang dilanjutkan dengan diskusi pleno. 


\section{PENGARUH MODEL PEMBELAJARAN THINK PAIR SHARE TERHADAP KEMAMPUAN MENYUNTING KARANGAN SISWA KELAS IX SMPN 1 CIMANGGU}

(Studi Eksperimen terhadap Siswa Kelas IX SMPN 1 Cimanggu)

Dengan model pembelajaran ini siswa dilatih bagaimana mengutarakan pendapat dan siswa juga belajar menghargai pendapat orang laindengan tetap mengacu pada materi/tujuan pembelajaran. Langkah-langkah model pembelajaran kooperatif think pair share sebagai berikut, yaitu :

a. Guru menyampaikan inti materi dan kompetensi yang ingin dicapai.

b. Siswa diminta untuk berpikir (thinking)

c. Guru mengajukan suatu pertanyaan atau masalah yang dikaitkan dengan pelajaran, dan meminta siswa menggunakan waktu beberapa menit untuk berpikir sendiri jawaban atau masalah.

d. Siswa diminta berpasangan (pairing)

Selanjutnya guru meminta siswa untuk berpasangan da mendiskusikan apa yang telah mereka peroleh. Interaksi selama waktu yang disediakan dapat menyatukan jawaban jika suatu pertanyaan yang diajukan menyatukan gagasan apabila suatu masalah khusus yang diidentifikasi. Secara normal guru member waktu tidak lebih dari 4 atau 5 menit untuk berpasangan.

e. Siswa diminta berbagi (sharing)

Pada langkah akhir, guru meminta pasangan-pasangan untuk berbagi dengan keseluruhan kelas yang telah mereka bicarakan. Hal ini efektif untuk berkeliling ruangan dari pasangan ke pasangan dan melanjutkan sampai sekitar sebagian pasangan mendapat kesempatan untuk melaporkan.

Berdasarkan uraian di atas, dapat disimpulkan bahwa model pembelajaran kooperatif think pair share adalah suatu model pembelajaran yang efektif untuk membuat variasi suasana pola diskusi dengan membagi siswa berpasangan untuk saling memecahkan suatu masalah.

\section{METODE PENELITIAN}

Metode penelitian merupakan kerangka, pola, atau rancangan yang menggambarkan alur dan arah penelitian yang didalamnya terdapat langkahlangkah atau tahap-tahap yang menunjukan suatu urutan kerja. Metode yang digunakan dalam penelitian ini adalah metode eksperimen (experimental method).

Menurut Hamdi (2014) metode penelitian membicarakan bagaimana secara berurut suatu penelitian dilakukan, yaitu dengan alat apa dan prosedur bagaimana suatu penelitian dilakukan. Sedangkan menurut Arikunto (2010) metode penelitian adalah cara berpikir, berbuat yang dipersiapkan, dengan baikbaik untuk mengadakan penelitian, dan untuk mencapai suatu tujuan tertentu.

Adapun penelitian yang akan dilakukan yaitu penelitian dengan menggunakan metode kuantitatif. Metode kuantitatif merupakan penelitian ilmiah yang sistematis menekankan analisisnya pada data berupa angka yang diolah dengan metode statistik.

Dalam penelitian ini, peneliti menggunakan kelas eksperimen dan kelas kontrol untuk mendapatkan data sehingga denga menggunakan kelas eksperimen dan kelas kontrol dapat diketahui jawaban dari hipotesis yang telah ditetapkan.

Objek penelitian yang penulis ambil adalah di SMP Negeri 1 Cimanggu, penulis memilih sampel siswa kelas IX-A tahun pelajaran 2019/2020 dengan jumlah 31 siswa, dengan 17 siswa laki-laki dan 14 siswa perempuan untuk meningkatkan kemampuan menyunting karangan melalui model pembelajaran kooperatif think pair share.

\section{HASIL PENELITIAN DAN PEMBAHASAN}

Tujuan penelitian ini adalah untuk mengetahui model pembelajaran Think Pair Share terhadap kemampuan menyunting karangan Siswa kelas IX SMP Negeri 1 Cimanggu tahun pelajaran 2019/2020. Tes awal dan tes akhir dilakukan di kelas. Tujuan diadakannya tes ini dilakukan adalah untuk mengetahui sejauh mana kemampuan menyunting karangan yang dimiliki oleh siswa setelah penerapan model pembelajaran Think Pair Share . Data hasil tes awal dan tes akhir yang didapatkan dari kelas.

1. Kegiatan Awal Pembelajaran 


\section{PENGARUH MODEL PEMBELAJARAN THINK PAIR SHARE TERHADAP \\ KEMAMPUAN MENYUNTING KARANGAN SISWA KELAS IX SMPN 1 CIMANGGU}

(Studi Eksperimen terhadap Siswa Kelas IX SMPN 1 Cimanggu)

Pendahuluan dimulai dengan elakukan pembukaan dengan salam pembuka, memanjatkan syukur kepada Tuhan YME dan berdna untuk memulai pembelaj 78 Memeriksa kehadiran peserta иıик sebagai sikap disiplin, menyiapkan fisik dan psikis peserta didik dalam mengawali kegiatan pembelajaran, Mengajukan pertanyaan yang ada keterkaitannya dengan pelajaran yang akan dilakukan. Selanjutnya, Guru menjelaskan mekanisme pelaksanaan pengalaman belajar sesuai dengan langkah-langkah pembelajaran.

2. Kegiatan Inti Pembelajaran

Peserta didik diberi motivasi atau rangsangan untuk memusatkan perhatian pada materi menyunting karangan dengan cara :

a. Melihat (tanpa atau dengan Alat)

b. Mengamati

c. Lembar kerja materi Pengertian menyunting karangan.

d. Pemberian contoh-contoh materi menyunting karangan untuk dapat dikembangkan peserta didik, dari media interaktif, dsb

3. Pengumpulan Data

Siswa bersama kelompoknya saling memberi dan menerima informasi yang mereka ketahui. Aktifitas tersebut difasilitasi oleh guru. Guru membimbing kegiatan ini agar siswa terarah dan terkondisikan.

4. Pengolahan Data

Selanjutnya data-data yang telah dikumpulkan bersama kemudian diolah untuk kembali di analisis dan diproyeksikan ke dalam menyunting karangani. Evaluasi dari pengolahan data tersebut adalah hasil tulisan menyunting karangan siswa berdasarkan cara menyunting dari data yang diperoleh dan dianalisis.

5. Pembuktian Data

Pada kegiatan ini siswa dapat menyampaikan hasil yang telah mereka lakukan. Data tersebut berupa langkah menyunting dan produknya yaitu hasil menyunting karangan itu sendiri. Guru membimbing dan mengarahkan siswa agar proses pembelajaran berjalan dengan efektif dan efisien.

6. Membuat Kesimpulan Mengenai Menyunting Karangan

Para peserta didik bersama kelompoknya menarik kesimpulan dari persoalaan yang telah dianalisis bersama dengan melakukan evaluasi bersama terhadap hasil menyunting karangan yang telah dibuatnya $\mathrm{Hal}$ ini agar hasil diskusi lebih mudah dipahami secara umum.

7. Kegiatan Penutupan Pembelajaran

Pada aktivitas ini peserta didik membuat resume dengan bimbingan guru tentang point-point penting yang muncul dalam kegiatan pembelajaran tentang materi menyunting karangan yang baru dilakukan. Guru memberikan kesempatan kepada salah satu perwakilan siswa untuk memberikan kesimpulan terhadap materi menyunting karangan memberi masukan serta kritikan yang membangun. Hal ini sebagai apresiasi terhadap siswa yang telah menjalani proses pembelajaran dengan baik.

8. Data Hasil Tes

Berdasarkan analisis terhadap data gain yang dilakukan dengan menggunakan uji t' telah menjawab masalah yang diajukan dalam penelitian ini. Berdasarkan skor ratarata gain yang diperoleh dari kelompok kontrol dan eksperimen yang menunjukan hasil bahwa gain kedua kelompok berdistribusi normal namun tidak homogen. Pengujian kenormalan untuk kelompok kontrol dan kelompok eksperimen dilakukan dengan pengujuian statistik yaitu uji Kolmogorov-Smirnov, sedangkan untuk melihat kehomogenan data skor yang diperoleh dari kedua kelompok sampel memiliki varians populasi yang sama atau berbeda digunakan uji Levene. Dari hasil perhitungan dengan menggunakan program komputer paket SPSS 24.0 yang telah dilakukan perhitungan sebelumnya, dapat disimpulkan bahwa terdapat perbedaan yang signifikan antara pembelajaran bahasa Indonesia materi menyunting karangan dengan menggunakan model pembelajaran 


\section{PENGARUH MODEL PEMBELAJARAN THINK PAIR SHARE TERHADAP \\ KEMAMPUAN MENYUNTING KARANGAN SISWA KELAS IX SMPN 1 \\ CIMANGGU}

(Studi Eksperimen terhadap Siswa Kelas IX SMPN 1 Cimanggu)

\begin{abstract}
kooperatif think pair share model konvensional terhadap kemampuan menyunting karangan siswa.
\end{abstract}

Tabel 1

Deskripsi Statistik Kemampuan

Menyunting Karangan

\begin{tabular}{|c|c|c|c|c|c|}
\hline \multirow{2}{*}{$\begin{array}{c}\text { Variabel } \\
\text { Menyunting } \\
\text { Karangan }\end{array}$} & \multicolumn{2}{|c|}{ Tes Awal } & \multicolumn{3}{|c|}{ Tes Akhir } \\
\hline & $\mathrm{N}$ & 31 & $\mathrm{~N}$ & & 31 \\
\hline & Nilai Min & 48 & $\begin{array}{l}\text { Nilai } \\
\text { Min }\end{array}$ & & 60 \\
\hline & Nilai Max & 84 & $\begin{array}{l}\text { Nilai } \\
\text { Max }\end{array}$ & & 86 \\
\hline & Median & 20 & Median & & 80 \\
\hline & Rata-rata & 69 & $\begin{array}{l}\text { Rata- } \\
\text { rata }\end{array}$ & & 77 \\
\hline $\begin{array}{l}\text { Uji } \\
\text { Normalitas }\end{array}$ & & & & $\begin{array}{l}\text { Sig.0 } \\
\text { 208 }\end{array}$ & \\
\hline $\begin{array}{l}\text { Uji } \\
\text { Homogenitas } \\
\text { Varians }\end{array}$ & & & & $\begin{array}{l}\text { Sig.0 } \\
, 418\end{array}$ & \\
\hline $\begin{array}{l}\text { Uji } \\
\text { Perbedaan } \\
\text { Rerata }\end{array}$ & & & & $\begin{array}{l}\text { Sig.0 } \\
, 00\end{array}$ & \\
\hline
\end{tabular}

signifikan dari penerapan model pembelajaran Think Pair Share pada pembelajaran menyunting karangan. hal ini terlihat dari nilai rata-rata posttest siswa berada pada angka 69 . Jika melihat pada tabel sebelumnya saat kegiatan pretest rata-rata siswa mendapatkan nilai 77. Artinya ada perubahan yang cukup signifikan dari sesudah pelaksanaan treatment. Untuk membuktikan bahwa hasil belajar tuntas, didasarkan pada standar ketuntasan yaitu Kriteria Ketentutasan Minimal (KKM) di SMP Negeri 1 Cimanggu yaitu > 70 . Kemampuan siswa dapat dikatakan meningkat dengan hasil siswa mendapatkan nilai signifikansi dua rerata 0,00 yang artinya terdapat peningkatan kemampuan menyunting karangan. Berdasarkan hasil tersebut penggunaan model pembelajaran Think Pair Share cukup efekkif digunakan pada pembelajaran menyunting karangan. hal ini dibuktikan dengan peningkatan yang cukup signifikan dari sebelum dan sesudahnya dengan peruabahan nilai rata-rata 69 menjadi 77. dibandingkan pembelajaran melalui

\section{KESIMPULAN}

Berdasarkan hasil pemaparan diatas, maka dapat ditarik kesimpulan sebagai berikut:

1. Terdapat peningkatan kemampuan menyunting karangan siswa SMP Negeri 1 Cimanggu kelas IX yang menggunakan model Pembelajaran Think Pair Share dengan siswa yang menggunakan pembelajaran dengan model konvensional.

2. Terdapat perbedaan yang signifikan antara siswa yang diberi model Pembelajaran Think Pair Share dengan siswa yang diberi model konvensional terhadap kemampuan menyunting karangan siswa.

3. Sebagian besar siswa menunjukan sikap yang potitif dalam pembelajaran bahasa Indonesia menggunakan Model Pembelajaran Think Pair Share yang ditunjukan dengan peningkatan kemampuan menyunting karangan.

\section{DAFTAR PUSTAKA}

Arifin, E. Zaenal dan S. Amran Tasai. (2008). Cermat Berbahasa Indonesia. Jakarta: Akademika Presindo.

Arikunto, Suharsimi. (2009). Dasar-dasar Evaluasi Pendidikan. Bandung: Bina Aksara.

Arikunto, Suharsimi. (2010). Prosedur Penelitian. Jakarta: Bina Aksara.

Departemen Pendidikan Nasional. (2008). Kamus Besar Bahasa Indonesia. Jakarta: PT Gramedia Pustaka Utama.

Hamdi, Asep Saepuloh. E. Baharuddin. 2014. Metode Penelitian Kuantitatif Aplikasi dalam Pendidikan. (Yogyakarta:Deepublisher)

Hartono, Bambang. (2010a). Dasar-dasar Penyuntingan. Semarang: UNNES

Hartono, Bambang. (2010b). Pengajaran Mikro. Semarang: Widya Karya.

Sugiyono. (2013). Memahami Penelitian Kualitatif. Bandung: Alfabeta. 